\title{
CONSUMO E DESPESAS SOCIAIS NO MUNICÍPIO DE CARNAUBAIS/RN: UMA ANÁLISE ORÇAMENTÁRIA A PARTIR DO MODELO DE JAMES O'CONNOR
}

\author{
Wiliam Gledson Silva ${ }^{1}$ \\ Gleison da Silva Fernandes ${ }^{2}$ \\ Vinícios Rodrigues Vieira Fernandes ${ }^{3}$
}

\begin{abstract}
RESUMO: Este artigo teve o objetivo de analisar o comportamento do orçamento municipal de Carnaubais/RN, partindo dos conceitos de consumo e despesas sociais do modelo de James O`Connor, no período de 2001/2018. Metodologicamente, usou-se uma revisão de literatura relacionada com os fundamentos teóricos do modelo de O`Connor e estatísticas descritivas para mensurar o comportamento orçamentário de Carnaubais/RN. Os resultados mostraram que o consumo social revelou significativa supremacia comparativamente às despesas sociais, apontando convergência do modelo de O`Connor e o teste empírico realizado.
\end{abstract}

Palavras-Chave: James O`Connor; Consumo Social; Despesas Sociais; Carnaubais/RN.

\section{CONSUMPTION AND SOCIAL EXPENSES IN THE MUNICIPALITY OF CARNAUBAIS/RN: A BUDGET ANALYSIS FROM THE MODEL OF JAMES O'CONNOR}

\begin{abstract}
This paper had to object analyze the Carnaubais/RN municipal budget behavior, start of James O'Connor model social consumption and expenditure concepts in the period 2001/2018. Methodologically, it used a literature review related with $\mathrm{O}^{\prime}$ Connor model theoretical foundations and descriptive statistics to measure Carnaubais/RN budget behavior. The results showed that the social consumption revealed significant supremacy comparatively to the social expenses, pointing out $\mathrm{O}^{`}$ Connor model and the performed empirical test convergence.
\end{abstract}

Keywords: James O'Connor; Social Consumption; Social Expenditure; Carnaubais/RN.

\footnotetext{
${ }^{1}$ Bacharel em ciências Econômicas (UFRN). Mestre em Economia (UFRN). Doutor em Ciências Sociais (UFRN). Pós-doc e, Ciências Sociais (UFRN). Professor Adjunto do Departamento de Economia da Universidade do Estado do Rio Grande do Norte - UERN.

${ }^{2}$ Bacharel em Sistema de Informação, pela Universidade do Estado da Bahia (UNEB - Campus II)

${ }^{3}$ Graduação em Ciências Econômicas pela Universidade Federal do Rio Grande do Norte (2011), mestrado em Economia pela Universidade Federal do Rio Grande do Norte (2014) e doutorado em Economia pela Universidade Federal de Uberlândia (2018).
} 


\section{INTRODUÇÃO}

Uma das questões mais representativas na discussão de entes municipais economicamente pequenos, a rigor, decorre da perspectiva da possibilidade de sustentabilidade fiscal, em outras palavras, é a capacidade que os municípios possuem da aplicação dos recursos públicos na forma de gastos em favor das diferentes classes sociais.

Para tanto, Silva Filho et al. (2011) mostram uma clara assimetria regional no Nordeste brasileiro, acentuando haver instâncias federativas dinâmicas margeadas por várias reduzidamente robustas do ponto de vista econômico, cuja principal fonte de financiamento dos dispêndios procede das denominadas transferências intergovernamentais, especialmente aquelas advindas da União.

De fato, Luna et al. (2017) mostram que o custeio da máquina pública revela a mais expressiva face de comprometimento das receitas governamentais com despesas nas esferas municipais, assinalando que a reduzida capacidade de arrecadação própria no Brasil, conforme ressalta Silva (2019 A), demonstra que o significado fundamental para que haja a chamada dependência fiscal emerge da baixa capacidade de arrecadação.

Assim, o autor supracitado sublinha haver no Brasil, categoricamente, um sistema ligado à estrutura político-administrativa firmado em relações federativas em que União, estados e Distrito Federal (DF) e os municípios conformam nuances tais que haja a distribuição de recursos e competências do Governo Federal aos demais entes subnacionais, podendo ser mais ou menos decentralizado.

Com efeito, a leitura de O'Connor (1977) parte das condições institucionais mencionadas, isto é, este estudo pretende capturar do autor enfatizado alguns conceitos capazes de compatibilizar os fundamentos teóricos e a estrutura políticoadministrativa brasileira, apontando que há traços relevantes a serem considerados no artigo.

O autor supracitado, o qual é assistido teoricamente por Afonso e Souza (1977) para uma análise empírica do Brasil, permite admitir a ocorrência do par de conceitos central à pesquisa em curso, a saber: Capital Social (KS) e Despesas Sociais (DS). O primeiro significa que o orçamento compromete as maiores parcelas dos recursos públicos com investimentos e consumo governamentais voltados às 
classes sociais dominantes, reservando dispêndios com assistência social e repressão como rubricas dedicadas aos agentes econômicos das classes menos representativas.

Com efeito, Silva (2019 B) mostra que o modelo de James O'Connor salvaguarda, teoricamente, a vinculação do Capital Social com as políticas de acumulação e, por extensão, as Despesas Sociais se relacionam com as denominadas políticas de legitimação, asseverando haver ações estatais capazes de conservar e, inclusive, ampliar as diferenças entre as classes, aplicando semelhante sistemática metodológica em um ente subnacional como o estado do Rio Grande do Norte.

Nesse sentido, a pesquisa em curso pretende discutir o comportamento fiscal do município de Carnaubais/RN, admitindo o orçamento público em termos de rubricas associadas ao Consumo Social (CS) e Despesas sociais imputadas a O Connor (1977) enquanto conceitos fundamentais de seu modelo teórico passíveis de revelar a estrutura orçamentária ao longo do período no limiar do novo milênio.

A hipótese deste artigo, via de regra, sustenta que o município de Carnaubais/RN apresenta uma forte supremacia do Consumo Social frente às Despesas Sociais, assinalando haver uma tendência de ampliação das diferenças das classes sociais carnaubaenses, ainda que haja esforços de dispêndios governamentais no ente enfatizado voltados ao social.

De fato, o objetivo do estudo perpassa pela tentativa de analisar o comportamento do orçamento público municipal de Carnaubais/RN, considerando os conceitos de Consumo e Despesas Sociais do modelo de James O'Connor, cujo período de investigação está compreendido entre os anos de 2001 a 2018.

Afinal, o artigo se encontra dividido em mais 3 seções além da introdução. A seguir, é necessário suscitar uma breve discussão teórica e a descrição dos procedimentos metodológicos; posteriormente, faz-se cabível analisar e discutir os principais resultados, resguardando o último item para algumas considerações finais.

\section{NOTAS TEÓRICAS E METODOLÓGICAS PROCEDENTES DO MODELO DE JAMES O' CONNOR PARA MUNICÍPIOS ECONOMICAMENTE PEQUENOS}

Esta seção tem a preocupação em apresentar alguns sumários aspectos teóricos e metodológicos ao desenvolvimento da pesquisa, quer dizer, faz-se 
necessário discutir sinteticamente o modelo de O`Connor e, posteriormente, é pertinente descrever os procedimentos principais ao alcance dos objetivos do trabalho aqui postado.

\subsection{CONCEITOS CENTRAIS}

Inicialmente, torna-se cabível resgatar os elementos fundamentais do modelo de O Connor (1977), o qual aponta haver um binômio conceitual correspondente ao capital social e despesas sociais, enfatizando uma diferenciação de classe em torno da dotação orçamentária de municípios, como Carnaubais/RN, sublinhando enquadramentos distintos nas prioridades das administrações públicas.

Assim, o autor supracitado menciona que há um par de maneiras de orçamentação. Por um lado o Capital Social está relacionado com o processo de acumulação capitalista, enquanto as Despesas Sociais conformam a chamada reprodução social da força de trabalho. Semelhantemente, Oliveira (1988) alcança conclusões bastante compatíveis na análise do fundo público.

De fato, O Connor (1977) identifica o KS em sendo composto pelo Investimento Social (IS) e o Consumo Social, onde o primeiro faz alusão ao processo de valorização capitalista mediante aos gastos públicos com infraestrutura e o segundo, claramente, associa-se ao contexto de redução no custo de produção da força de trabalho, geralmente através de dispêndios com educação, saúde, previdência social, habitação, dentre outros tipos de despesas públicas.

É de bom alvitre frisar, por sua vez, que a redução do custo da força de trabalho é vital a essa última perspectiva, pois trabalhadores mais hábeis reduzem a necessidade de que os capitalistas ampliem a contratação de outros trabalhadores, permitindo haver um número menor e níveis produtivos equiparáveis, conforme admitem Oliveira (1988) e Offe (1990).

Já o significado de Despesas Sociais, categoricamente, procede da tentativa de gerar a denominada legitimação, ou seja, a dotação orçamentária via rubricas de assistência social e repressão corresponde às políticas de legitimação, reservando ao enquadramento do capital social a sinalização das políticas de acumulação, acentuando diferenças de classes sociais orçamentadas para o modelo aqui salientado, segundo evidências recuperadas por Silva (2019 B) quando esse analisa o orçamento estadual potiguar ao longo de ciclos do Plano Plurianual (PPA). 
Em reforço ao antes exposto, Afonso e Souza (1977) aplicam o modelo de James O`Connor para o Brasil durante o período militar, cuja característica emblemática se dá mediante a centralização fiscal constitucionalmente instituída, onde tais contornos apontam ocorrer uma maior contundência da administração pública no sentido de determinar nacionalmente as formas assimétricas de atendimento das demandas das diferentes classes sociais.

Acrescente-se a isso, a rigor, que Salvador (2008) quando analisa o fundo público demonstra, para além da discussão de Oliveira (1988), a conformação do fundo público em um país emergente como o Brasil, sinalizando haver um terreno financeiro em escala mundial capaz de influenciar dramaticamente nas condições fiscais brasileiras, impactando federativamente.

Torna-se importante destacar, segundo Silva (2019 A), que entes subnacionais brasileiros em especial, claramente, demonstram uma autonomia relativa do ponto de vista da formulação das políticas públicas mais representativas, cuja explicação procede da estrutura político-administrativa federativa com viés de descentralização significativamente superior em 1988 comparativamente ao período militar.

Assim, a compreensão anterior permite observar que políticas de acumulação e legitimação, a partir da leitura de O`Connor (1977), preconizam coexistir formas fiscalmente autônomas de considerar as demandas dos membros das classes dominante e dominada, recuperando a percepção teórica de Nicos Poulantzas apontada por Silva (2019 A), quando esse último admite ser preponderante evidenciar uma presença estatal capitalista posicionada para além das classes e não uma mera reprodução da classe dominante e/ou uma colocação independente dos interesses de classe.

Nesse sentido, Silva (2017) preconiza que a leitura de Poulantzas acentua ocorrer, por sua vez, políticas de legitimação compatíveis com a impossibilidade de haver conflitos sociais decorrentes da luta de classes, sendo tal a razão pela forma de assimetria orçamentária proveniente das bases do modelo de James O`Connor, sistematizando nuances institucionalizadas na perspectiva das diferenças entre capitalistas e trabalhadores, conforme Silva (2019 B).

Em acréscimo aos apontamentos precedentes, Silva Filho et al. $(2011 ; 2017)$ mostram haver no Brasil, categoricamente, um enquadramento municipal federativamente bastante dependente diante das transferências 
intergovernamentais, sendo a mais substancial relacionada com o Fundo de Participação dos Municípios (FPM), de origem Federal, sublinhando possibilidades mais factíveis dos entes municipais realizarem políticas voltadas à acumulação e/ou legitimação ao orçamentar tais demandas.

No que diz respeito aos gastos públicos municipalmente, faz-se necessário mencionar que o custo com folha de pagamentos do funcionalismo, particularmente na região Nordeste brasileira, apresenta a maior participação da aplicação dos recursos obtidos, reservando aos demais itens orçamentários resíduos postados como prioridades das políticas públicas formuladas no local, de acordo com ressalvas de Luna et al. (2017).

De fato, fazer referência às receitas e despesas municipais nordestinas, a rigor, possibilita observar um par de aspectos, a saber: dependência fiscal e comprometimento com pessoal bastante elevados. O significado disso, na verdade, demonstra que os municípios economicamente pequenos demandam maiores quantias de repasses para financiar seus dispêndios, geralmente relativos aos pagamentos dos funcionários públicos, daí ser tal a característica de entes federativos como Carnaubais/RN.

Nesse sentido, os resíduos orçamentários municipais, especificamente de uma instância governamental a exemplo de Carnaubais/RN, via de regra, sugerem haver no custeio da máquina pública local notável inclinação em financiar gastos voltados não aos Investimentos Sociais e sim ao Consumo Social, garantindo o processo de acumulação capitalista, ainda que em um município economicamente pequeno.

\subsection{PROCEDIMENTOS METODOLÓGICOS}

Em linhas gerais, claramente, o estudo agora sinalizado trata de uma leitura de orientação dedutiva, já que se parte das explicações gerais sobre o tema das finanças públicas, passando pela ideia orçamentária repousante no município de Carnaubais/RN, tomando como referência teórica a análise feita no modelo de O`Connor (1977). 
Geralmente, o que se evidencia é a adoção de análises para países, semelhantemente ao realizado por Afonso e Souza (1977) no Brasil durante o período militar.

Para atingir o objetivo do estudo, utilizam-se dados secundários, realizandose uma análise mediante estatística descritiva. Os dados foram coletados na Secretaria do Tesouro Nacional (STN), mais precisamente no item Finanças Municipais do Brasil (FINBRA), abrangendo o período 2001-2018, corte temporal convergente ao conjunto de anos imediatamente após a implementação da Lei de Responsabilidade Fiscal (LRF) até o período mais recente.

Especificamente, uma primeira adaptação metodológica, via de regra, trata de reduzir o alcance político-administrativo de uma amplitude governamental central para o escopo do município, seguindo o que Silva (2017) preconiza para o estado do Rio Grande do Norte, permitindo expandir tal perspectiva ao nível federativo municipal e, similarmente, produzir nuances capazes de fortalecer tais contornos investigativos particulares.

Uma segunda modificação metodológica, claramente, corresponde ao conceito de Despesas Sociais, em que O`Connor (1977) identifica como a combinação da assistência social e repressão (gastos militares), reservando para as instâncias municipais a apresentação, quando muito, das guardas municipais na condição de aproximação da ideia de forças armadas, fato esse não vislumbrado em Carnaubais/RN, viabilizando serem as Despesas Sociais resumidas ao aspecto da assistência social.

Já em uma terceira prerrogativa, a rigor, o Capital Social não conserva com vigor econômico os denominados Investimentos Sociais, pois as cifras dedicadas a tal rubrica municipal revela valores insignificantes quando há registro anual, acentuando perpassar pelo Consumo Social a questão da acumulação através do processo de redução do custo de produção da força de trabalho.

Acrescente-se, especialmente, a forma de mensuração dos conceitos de Consumo e Despesas Sociais carnaubaenses, quer dizer, Silva (2017) mostra ser pertinente utilizar como parâmetro de medição das rubricas de gastos a Receita Total (RT), cujas participações relativas demonstram o peso orçamentário das rubricas e, portanto, o enquadramento das classes sociais ao longo dos anos de 2001 a 2018 enquanto período de análise aqui selecionado. 
Afinal, esta seção traz uma síntese teórico-metodológica essencial ao alcance do esperado no artigo, cuja preocupação é sublinhar os alicerces da pesquisa, bem como lançar mão das condições para discussão dos resultados postada no item subsequente do estudo em curso nestas páginas.

\section{NOTAS SOBRE O COMPORTAMENTO ORÇAMENTÁRIO DE CARNAUBAIS/RN A PARTIR DOS CONCEITOS DE CONSUMO E DESPESAS SOCIAIS}

Nesta seção, na verdade, procura-se esmiuçar os desdobramentos da pesquisa sobre o município de Carnaubais/RN, introduzindo-se os resultados alcançados, em linhas gerais no estudo. Aqui, passa-se a conhecer a parte mensurável da pesquisa, conhecendo as receitas, despesas e o comportamento dessas ao longo do período analisado, partindo de um plano metodológico previamente determinado.

O artigo, por sua vez, pretende revelar com base na leitura de $\mathrm{O}^{`}$ Connor (1977), claramente, mecanismos capazes de esmiuçar prerrogativas de compreensão da dotação orçamentária no sentido de haver a aplicação conceitual de Capital e Despesas Sociais, considerando, prioritariamente, o Consumo Social na condição de elemento representativo no processo de acumulação capitalista no plano municipal.

Por conseguinte, Luna et al. (2017) declaram que os gastos públicos no local passam a ser bastante importantes, tendo em vista, especificamente, que a demanda social é expressiva e que se faz premente a presença do ente público (no caso estudado, Prefeitura), para que se atendam as necessidades da população, em decorrência da instância governamental conhecer as reais demandas locais.

Assim, os conceitos do modelo de O'Connor (1977) indicam que o Consumo Social, pelo menos diante da leitura empírica de Silva (2017), assume uma posição destacada no âmbito subnacional brasileiro, já que os Investimentos Sociais provenientes da esfera pública se conformam a um patamar diminuto fiscalmente, sendo plausível admitir para o aspecto das políticas de acumulação tal corolário teórico repousante na compreensão do objeto aqui selecionado.

De fato, a Tabela 1 a seguir preconiza haver, particularmente, um panorama mais geral quanto ao comportamento das variáveis constituídas pelas rubricas 
fiscais de Carnaubais/RN entre os anos de 2001 a 2018. Nessas circunstâncias, metodologicamente, o orçamento deve ser construído a partir da seguinte estrutura, simplificadamente: Receita Total, Gastos com Educação (GE), Saúde (GS), Previdência Social (GPS), Habitação (GH) e os Gastos com Assistência Social (GAS).

Com efeito, o Consumo Social reúne o somatório do GE, GS, GPS e GH como proporção da RT, reservando para as Despesas Sociais a relação entre GAS e RT, conformando a leitura proveniente do modelo de James O'Connor. Logo, o conjunto de dispêndios antes postado denota um desenho inicial municipal no período observado, lançando as bases para a análise aqui empreendida.

Os resultados da Tabela 1, na verdade, mostram que em termos médios as despesas com educação representam aquelas mais expressivas, sendo perseguida por dispêndios com saúde, previdência e assistência sociais e habitação, denotando haver uma supremacia em valores absolutos do Consumo Social frente às Despesas Sociais, acentuando a validade teórica do modelo de O`Connor (1977).

Tal constatação empírica, a rigor, traduz uma clara característica de dominação de classe expressa orçamentariamente, onde os capitalistas em Carnaubais/RN exercem determinado tipo de influência no ente público local, sendo possível atestar politicamente 0 alcance de resultados favoráveis aos interesses da classe dominante, conforme descrição advinda dos estudos de Silva (2017; 2019 B). Gomes e Mac Dowell (2000), por sua vez, corroboram com os autores enfatizados no sentido da aceitação dos municípios economicamente pequenos serem sustentados pelas transferências intergovernamentais de origem Federal. 
Tabela 1 - Receitas e gastos do município de Carnaubais/RN (2001-2018).

\begin{tabular}{ccccccc}
\hline Período & RT & GE & GS & GPS & GH & GAS \\
\hline $\mathbf{2 0 0 1}$ & $6.850 .479,37$ & $2.007 .198,00$ & $138.179,00$ & $241.447,86$ & $775.717,00$ & $721.073,00$ \\
\hline $\mathbf{2 0 0 2}$ & $8.013 .464,59$ & $1.859 .638,71$ & $1.406 .640,69$ & $412.102,89$ & $236.046,30$ & $840.140,70$ \\
\hline $\mathbf{2 0 0 3}$ & $8.866 .254,57$ & $2.264 .544,28$ & $1.700 .897,74$ & $544.206,91$ & $202.357,22$ & $793.765,92$ \\
\hline $\mathbf{2 0 0 4}$ & $9.271 .458,16$ & $2.340 .845,41$ & $1.733 .365,69$ & $491.111,38$ & $205.874,66$ & $609.361,75$ \\
\hline $\mathbf{2 0 0 5}$ & $10.430 .165,56$ & $2.894 .939,86$ & $2.055 .325,37$ & $704.236,84$ & $80.805,23$ & $715.493,69$ \\
\hline $\mathbf{2 0 0 6}$ & $11.521 .233,22$ & $3.377 .561,64$ & $2.434 .156,77$ & $960.607,95$ & $255.126,84$ & $864.797,21$ \\
\hline $\mathbf{2 0 0 7}$ & $12.020 .569,34$ & $2.281 .073,98$ & $2.281 .073,98$ & $996.406,04$ & $429.448,45$ & $960.224,41$ \\
\hline $\mathbf{2 0 0 8}$ & $15.084 .972,17$ & $4.283 .243,36$ & $3.058 .639,49$ & $949.501,93$ & $130.000,00$ & $1.044 .479,31$ \\
\hline $\mathbf{2 0 0 9}$ & $15.552 .501,72$ & $4.992 .936,44$ & $3.469 .987,15$ & $1.103 .171,37$ & $492.141,60$ & $1.239 .842,76$ \\
\hline $\mathbf{2 0 1 0}$ & $16.797 .565,69$ & $6.966 .162,09$ & $3.629 .689,58$ & $1.081 .682,79$ & $161.451,00$ & $951.358,39$ \\
\hline $\mathbf{2 0 1 1}$ & $20.858 .673,15$ & $6.289 .801,74$ & $4.528 .738,51$ & $1.340 .843,85$ & $219.781,05$ & $1.044 .988,03$ \\
\hline $\mathbf{2 0 1 2}$ & $19.849 .042,32$ & $6.503 .188,79$ & $4.350 .348,05$ & $1.405 .636,89$ & $180.151,00$ & $1.136 .010,05$ \\
\hline $\mathbf{2 0 1 3}$ & $21.107 .710,92$ & $6.987 .690,78$ & $4.659 .698,57$ & $1.506 .192,73$ & $161.861,78$ & $1.177 .079,52$ \\
\hline $\mathbf{2 0 1 4}$ & $22.366 .379,53$ & $7.472 .192,77$ & $4.969 .049,09$ & $1.606 .748,58$ & $143.572,57$ & 1218148,999 \\
\hline $\mathbf{2 0 1 5}$ & $23.625 .048,13$ & $7.956 .694,76$ & $5.278 .399,62$ & $1.707 .304,43$ & $125.283,35$ & $1.259 .218,47$ \\
\hline $\mathbf{2 0 1 6}$ & $24.883 .716,74$ & $8.441 .196,75$ & $5.587 .750,14$ & $1.807 .860,28$ & $106.994,13$ & $1.300 .287,95$ \\
\hline $\mathbf{2 0 1 7}$ & $26.142 .385,34$ & $8.925 .698,74$ & $5.897 .100,66$ & $1.908 .416,12$ & $88.704,91$ & $1.341 .357,42$ \\
\hline $\mathbf{2 0 1 8}$ & $27.401 .053,95$ & $9.410 .200,72$ & $6.206 .451,18$ & $2.008 .971,97$ & $70.415,70$ & $1.382 .426,90$ \\
\hline Média & $16.702 .370,80$ & $5.291 .933,82$ & $3.521 .416,18$ & $1.154 .247,27$ & $225.874,04$ & $1.033 .336,36$ \\
\hline
\end{tabular}

Fonte: Elaboração própria com base em dados do FINBRA/STN (2019).

De posse da trajetória do Consumo Social expressa no Gráfico 1, torna-se cabível salientar que tal variável revela ao longo dos anos observados flagrante comportamento tendencial de acumulação capitalista, isto é, as rubricas consideradas traçam possibilidades de redução no custo de produção da força de trabalho, indicando nuances governamentais beneficiadoras à classe dominante, segundo apontamentos nos estudos de Afonso e Souza (1977), Oliveira (1988) e Silva (2017). 
Gráfico 1 - Gastos com Consumo Social na RT do município de Carnaubais/RN (2001-2018).

0.80

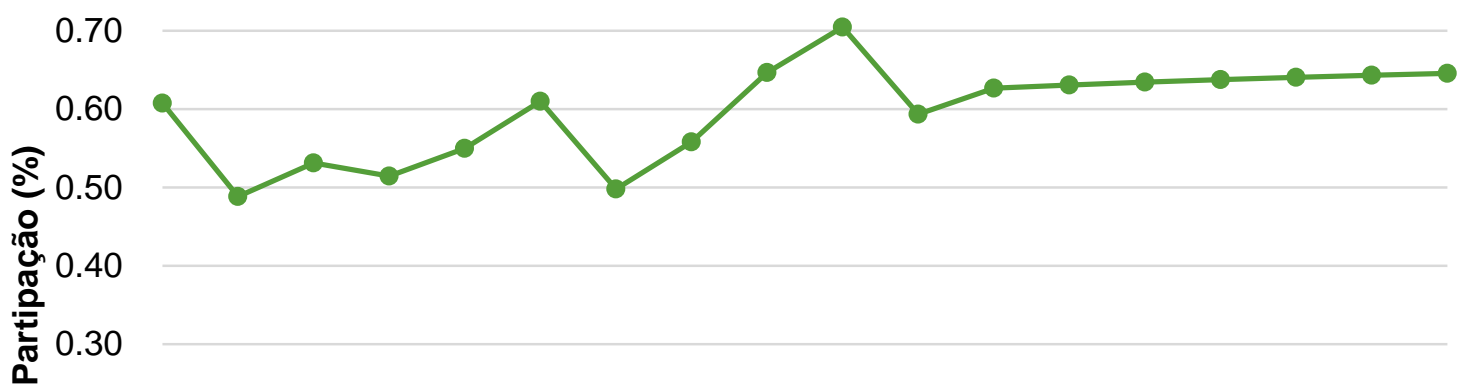

0.20

0.10

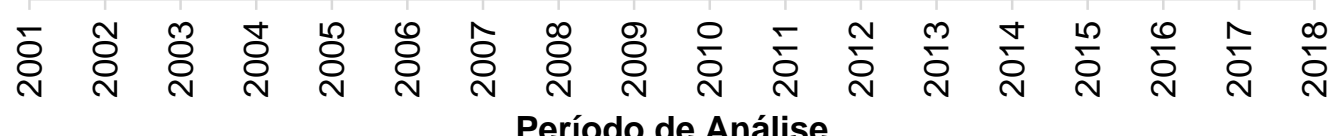

Fonte: Elaboração própria com base em dados do FINBRA/STN (2019).

Assim, o exposto anteriormente, a rigor, demonstra que a perspectiva teórica alcança determinado vigor analítico, pois são captados esforços governamentais em nível municipal no sentido de ser prioridade fornecer meios ao capital, ainda que seja esse pouco robusto, sendo obtida uma fotografia bastante relevante em Carnaubais/RN nos anos examinados.

A partir da explicitação constante no Gráfico 2, particularmente, é importante ressaltar que o comportamento das Despesas Sociais revela haver uma tendência de reprodução social da força de trabalho bastante diminuta, resguardando cifras significativamente menores ao vislumbrado no consumo social, compatibilizando com a conclusão teórica do modelo de O`Connor (1977), de maneira que tal política de legitimação reproduz as diferenciações sociais, a exemplo dos realces de Silva (2019 B). 
Gráfico 2 - Gasto com Despesas Sociais na RT do município de Carnaubais/RN (2001/2018).

0.14

0.12

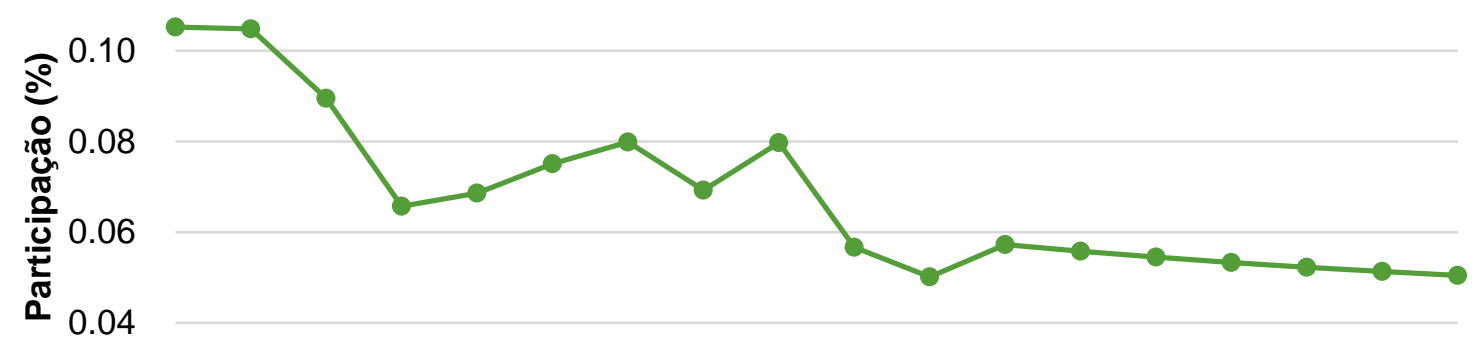

0.02

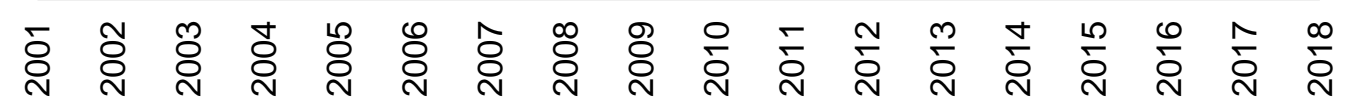
Período de Análise

Fonte: Elaboração própria com base em dados do FINBRA/STN (2019).

Ao observar os resultados apresentados na Tabela 2, especialmente, é pertinente salientar que o Consumo Social representa praticamente toda a parcela orçamentária mensurada pelas cifras antes expressas, reservando para as Despesas Sociais resíduos destinados à classe trabalhadora, mostrando em termos médios a conservação da validade teórica do modelo de O'Connor (1977).

Entretanto, a integralidade das evidências atestadas nesta seção, a rigor, demonstra nuances dignas de ressalva, quer dizer, um município como Carnaubais/RN sinaliza alguns elementos importantes a serem mencionados, por um lado as diferenças de classe persistem em ocorrer devido à dotação orçamentária assimétrica, por outro lado a baixa capacidade de arrecadação municipal impossibilita haver maiores gastos nas demais áreas. 
Tabela 2 - Consumo e Despesas Sociais por indicadores do município de Carnaubais/RN (2001/2018, em percentuais).

\begin{tabular}{c|ccccc}
\hline Período & GE/T & GS/RT & GPS/RT & GH/RT & GAS/RT \\
\hline $\mathbf{2 0 0 1}$ & 29 & 17 & 4 & 11 & 11 \\
\hline $\mathbf{2 0 0 2}$ & 23 & 18 & 5 & 3 & 10 \\
\hline $\mathbf{2 0 0 3}$ & 26 & 19 & 6 & 2 & 9 \\
\hline $\mathbf{2 0 0 4}$ & 25 & 19 & 5 & 2 & 7 \\
\hline $\mathbf{2 0 0 5}$ & 28 & 20 & 7 & 2 & 8 \\
\hline $\mathbf{2 0 0 6}$ & 29 & 21 & 8 & 4 & 8 \\
\hline $\mathbf{2 0 0 7}$ & 19 & 19 & 8 & 1 & 7 \\
\hline $\mathbf{2 0 0 8}$ & 28 & 20 & 6 & 3 & 8 \\
\hline $\mathbf{2 0 0 9}$ & 32 & 22 & 7 & 1 & 6 \\
\hline $\mathbf{2 0 1 0}$ & 41 & 22 & 6 & 1 & 6 \\
\hline $\mathbf{2 0 1 1}$ & 30 & 22 & 6 & 1 & 6 \\
\hline $\mathbf{2 0 1 2}$ & 33 & 22 & 7 & 1 & 5 \\
\hline $\mathbf{2 0 1 3}$ & 33 & 22 & 7 & 1 & 5 \\
\hline $\mathbf{2 0 1 4}$ & 33 & 22 & 7 & 0 & 5 \\
\hline $\mathbf{2 0 1 5}$ & 34 & 22 & 7 & 0 & 5 \\
\hline $\mathbf{2 0 1 6}$ & 34 & 22 & 7 & 0 & 7 \\
\hline $\mathbf{2 0 1 7}$ & 34 & 23 & 7 & 2 & \\
\hline $\mathbf{2 0 1 8}$ & 34 & 23 & 7 & 7 & 1 \\
\hline MÉDIA: & 30 & 21 & 7 &
\end{tabular}

Fonte: Elaboração própria com base em dados do FINBRA/STN (2019).

De fato, o cenário fiscalmente dependente do município enfatizado, claramente, não descaracteriza a condição de que o ente federativo aqui admitido reproduz a conservação das distinções de classe, ou seja, independentemente da amplitude da administração pública o orçamento deve estabelecer uma dotação destacadamente favorável aos membros da classe dominante, sendo pertinente adotar o modelo de James O`Connor para semelhantes tipologias analíticas.

Assim, o cenário descrito revela a aceitação da hipótese do artigo e, semelhantemente, a percepção da robustez do modelo de James O Connor no sentido de alcançar resultados pertinentes ao modo de compreensão marxista, onde as classes sociais atravessam o setor público enquanto Estado autonomamente relativo, a partir de Silva (2019 A) quando recupera o conceito de aparelho estatal de Nicos Poulantzas.

Portanto, esta seção traz apontamentos capazes de salientar como o orçamento municipal de Carnaubais/RN reproduz assimetrias sociais na sua dotação, admitindo um corte temporal iniciado logo após o advento da Lei de Responsabilidade Fiscal, estendendo até 2018, passando por diversos sobressaltos 
econômicos mundo a fora, refletindo no ente municipal aqui selecionado nesta pesquisa.

\section{CONSIDERAÇÕES FINAIS}

O presente estudo teve como objetivo analisar o comportamento orçamentário do município de Carnaubais/RN, partindo dos conceitos de Consumo e Despesas Sociais, com base no modelo de James O Connor, entre os anos de 2001 a 2018. Houve o estabelecimento de relações entre variáveis, a partir do uso de técnicas padronizadas de coleta de dados, com a captura de informações no banco de dados da STN, especificamente no item FINBRA.

Ressaltou-se, claramente, que o Capital Social se reservou às rubricas ligadas exclusivamente ao Consumo Social, pois corresponderam a uma redução no custo de produção da força de trabalho. As Despesas Sociais restringiram-se à assistência social, constituindo uma nuance peculiar deste trabalho.

Observou-se que o Consumo Social demonstrou cifras bastante significativas diante do item relativo às Despesas Sociais, sublinhando haver, categoricamente, uma flagrante diferenciação social presente no município de Carnaubais/RN, cuja reprodução de tais distorções orçamentariamente, na verdade, possibilitou ocorrer tendências de fortalecimento das desigualdades socialmente.

Assim, quando a Despesa Social atingiu seu maior montante, isso no ano de 2018, sua participação na receita era apenas de 5\%. Em síntese foi possível justificar tal resultado pelo fato desta rubrica não pertencer à reprodução ampliada do capital nem tão pouco traduzir-se em gastos com capital massivo para o retorno qualificado da força de trabalho.

Nesse sentido foi cabível destacar que a análise aqui executada, ainda que numa perspectiva municipal, contribuiu de forma plausível e contundente no sentido de verificar que os gastos sociais nas áreas de Educação, Saúde e Previdência Social representaram um montante expressivo dentro do orçamento de qualquer ente federativo do Brasil, não sendo diferente com o ente municipal analisado.

Com efeito, o aporte teórico de James O`Connor permitiu captar as mencionadas assimetrias de classe a partir do orçamento público, conformando em um modelo de análise capaz de viabilizar discussões acerca das distinções 
classistas em torno do orçamento público municipal na Federação brasileira especificamente, acentuando ser mediante o ente carnaubaense que se aplicou procedimento inédito da relação teórica de O`Connor e aspectos de finanças a esses moldes no local.

Finalmente, alcançou-se no término deste artigo a aceitação da hipótese da pesquisa, assinalando haver uma contínua diferença de classe em Carnaubais/RN, atribuindo ao orçamento público municipal explicitar as assimetrias sociais. De fato, os futuros trabalhos nesta perspectiva, claramente, poderiam acrescentar nuances de expansão de entes municipais e adoção de modelagem econométrica para estimar comportamentos para além do obtido no estudo agora finalizado.

\section{REFERÊNCIAS}

AFONSO, C. A.; SOUZA, H. de. O Estado e o desenvolvimento capitalista no Brasil: a crise fiscal. Rio de Janeiro: Paz e Terra, 1977.

GOMES, G. M; MAC DOWELL, M. C. Descentralização Política, Federalismo Fiscal e Criação de Municípios: o que é mau para o econômico nem sempre é bom para o social. Texto para discussão, Brasília, n. 706, IPEA, fev. 2000.

LUNA, T. B. DE; SILVA, W. G; SILVA FILHO, L. A. Despesas municipais nordestinas: uma análise empírica a partir da Lei de Responsabilidade Fiscal (LRF). Revista Econômica do Nordeste. v. 48, n. 2. p. 101-110, 2017.

O CONNOR, J. USA: a crise do Estado capitalista. Rio de Janeiro: Paz e Terra, 1977.

OLIVEIRA, F. de. O surgimento do antivalor: capital, força de trabalho e fundo público. Novos Estudos, n. 22, 1988.

OFFE, C. Sistema educacional, sistema ocupacional e política da educação: contribuição à determinação das funções sociais do sistema educacional. Educação e Sociedade, n.35, p. 9-59, abr.1990.

SALVADOR, E. S. Fundo Público no Brasil: financiamento e destino dos recursos da seguridade social (2000 a 2007). 2008. Tese (Doutorado) - Instituto de Ciências Humanas, Universidade de Brasília, Brasília, DF, 2008.

SILVA FILHO, L. A.; et al. Comportamento das receitas próprias municipais da Bahia e de Pernambuco: análise do primeiro decênio do século XXI. Revista de Economia Mackenzie, v. 14, n. 1, p. 107-122, 2017. 
SILVA FILHO, L. A.; et al. Considerações sobre receitas municipais em estados do Nordeste: comparação entre Bahia, Ceará e Piauí 2007. Revista Econômica do Nordeste, v. 42, n. 2, p. 409-424, 2011.

SILVA, W. G. Autonomia relativa e descentralização fiscal: uma análise da arrecadação estadual do Rio Grande do Norte. Revista Paranaense de Desenvolvimento, v. 40, n. 136, p. 65-78, 2019.

SILVA, W. G. Diferenciação da política social na composição orçamentária potiguar: uma análise a partir de James O Connor. Revista de Economia Regional, Urbana e do Trabalho, v. 8, n. 1, p. 131-150, 2019.

SILVA, W. G. Fundo Público e a Programação e Execução Orçamentárias no Rio Grande do Norte: Uma Análise a Partir do Plano Plurianual 2004/2015. 2017. Tese (Doutorado) - Programa de Pós-Graduação em Ciências Sociais, Universidade Federal do Rio Grande do Norte, Natal, 2017.

Recebido em: junho de 2020

Aceito em: outubro de 2020 